\title{
Localized Ultraviolet Laser Microbeam Irradiation of Early Drosophila Embryos: Fate Maps Based on Location and Frequency of Adult Defects ${ }^{1}$
}

\author{
Margit Lohs-Schardin, ${ }^{*}$ Klaus Sander, ${ }^{*}, 2$ Christoph Cremer, $\dagger$ \\ Thomas Cremer, $\dagger$ and Christian Zorn $\dagger$ \\ * Biologisches Institut I (Zoologie) der Universität und † Institut für Humangenetik der Universität, D-7800 \\ Freiburg i.Br., West Germany
}

Received May 22, 1978; accepted in revised form September 1, 1978

\begin{abstract}
Drosophila embryos were locally irradiated with a $257-\mathrm{nm}$ laser microbeam during blastoderm and germ band stages. Depending on stage and beam diameter $(10-30 \mu \mathrm{m})$, from 0 to 45 nuclei were exposed to the uv radiation. The doses used, 5 or $10 \mathrm{erg}$, did not eliminate nuclei or cells at once, but up to $50 \%$ of the adult survivors from irradiated eggs carried defects in the thorax. These were scored with reference to the imaginal discs from which the affected structures derive. For each thoracic disc a "target center" was calculated as the weighted mean value of all bearn locations affecting the respective adult derivatives. The target centers for the germ band stage map within the respective germ band segments. The pattern of target centers for the blastoderm stage is comparable to the thoracic region of published fate maps, and the distances between adjacent leg centers (approximately three cell diameters) agree with recent evidence based on mosaic flies. We discuss the question whether the target centers mark the position of the respective disc progenitor cells at the stages of irradiation and conclude that these positions are rendered rather correctly at least with reference to the longitudinal egg axis.
\end{abstract}

\section{INTRODUCTION}

The elimination of defined embryonic cells or small cell groups in order to elucidate their prospective fates was among the earliest experimental methods of developmental biology. In insects, such experiments were first performed by Hegner (1910) and Geigy (1931) on the prospective germ cells and by Seidel (1935) on different somatic regions of the incipient germ anlage. Prospective somatic cells have been eliminated from blastoderm or germ band stages of Drosophila by pricking the egg (Howland and Child, 1935; Bownes and Sang, 1974a; Mertens, 1977), by local cautery (Bownes, 1975; Bownes and Sang, 1974b), or by local uv irradiation (Hathaway and Selman, 1961; Nöthiger and Strub,

${ }^{3}$ Supported by the Deutsche Forschungsgemeinschaft, SFB 46 .

${ }^{2}$ To whom requests for reprints should be addressed.
1972).

The uv laser microbeam constructed originally for the irradiation of selected areas within individual cells (Cremer et al., 1974) permits inactivation of considerably smaller cell groups than the irradiation techniques used in the previous studies, and this in a much more controlled fashion than with cautery or by pricking the egg. We have used this instrument to irradiate small patches of cells in defined regions of the blastoderm and the germ band in Drosophila melanogaster. The frequency and location of externally visible defects in the ensuing flies were scored with reference to the discs from which the affected cuticular structures derive. In this communication, we use these data to construct fate maps for the irradiated stages. The accuracy of these maps, although probably superior to that of any previous defect fate maps for the Drosophila embryo, is restricted by 
limitations inherent in the defect mapping method as such. Yet we propose that our data reveal the absolute blastodermal positions, with reference to the longitudinal egg axis, of the progenitor cells for the adult thorax, and thus can serve to place the fate maps derived from mosaic flies (for review, see Hall et al., 1976) correctly on the blastoderm.

\section{MATERIALS AND METHODS}

Egg collection and rearing conditions. Flies of the Oregon K stock of Drosophila melanogaster were allowed to lay eggs on agar plates for $20 \mathrm{~min}$ (blastoderm irradiations) or $40 \mathrm{~min}$ (germ band irradiations). Eggs were washed off the agar plate and submerged in a weak solution of $\mathrm{NaOCl}$ until the chorion was nearly transparent, and then washed in tap water; thus the chorion filaments were preserved as an aid for correct orientation. Rearing temperature from egg laying to the time of irradiation varied between 18 and $25^{\circ} \mathrm{C}$.

Stages irradiated. Eggs were irradiated at various stages $1.5-4 \mathrm{hr}$ after the egg laying period (Table 1) and after completion of the germ band (age 10-15 hr at $25-18^{\circ} \mathrm{C}$ ). The exact stage of development was acertained under the compound microscope (magnification 320x) for each egg immediately before irradiation.

Ultraviolet laser microbeam. The setup used for irradiation (Cremer et al., 1974) employs a laser system emitting coherent light of $257 \mathrm{~nm}$ wavelength. The beam was focused on the egg from above through a Zeiss Ultrafluar condenser n.a. 0.8 which also served as the front lens (magnification $32 \times$ ) of the compound microscope used for observation and alignment. The aperture stop of the condenser was set to approximately n.a. 0.3. The diameter of the uv beam in the plane of observation was established by focusing the observation optics on the surface of a fluorescent slide and measuring the visible spot caused by the incident uv beam. The location of this spot in the field of view was checked with an eyepiece grid at the outset and between consecutive series of irradiations; it was found to remain constant. Energy flow was always set to approximately $1 \mathrm{erg} / \mathrm{sec}$ while the duration of irradiation and the beam diameter in the plane of observation were varied. The energy reaching the cells of the embryo cannot be measured directly. It could be estimated on the basis that, with the wavelength used, the covering foil (see below) absorbs about $15 \%$ of the incident energy, and the vitelline membrane about $30 \%$ (Bownes and Kalthoff, 1974); the absorption by the remnants of the chorion is not known.

Orientation of eggs for irradiation. About 10 eggs at a time were placed in a drop of water on a microscope slide and covered with a piece of uv-transmitting

TABLE 1

Stages Irradated before and during Blastoderm Formation

\begin{tabular}{|c|c|c|c|c|}
\hline \multirow[t]{2}{*}{ Stage ${ }^{a}$} & \multirow[t]{2}{*}{$\mathrm{Age}^{b}$} & \multirow[t]{2}{*}{ Criteria } & \multicolumn{2}{|c|}{ Number of nuclei } \\
\hline & & & $\begin{array}{l}\text { In egg } \\
\text { surface }^{c}\end{array}$ & $\begin{array}{l}\text { In } 10 \mu \mathrm{m} \\
\text { field }\end{array}$ \\
\hline $0 \quad(9)$ & $1.5-2$ & Cleavage nuclei start migration toward surface & & $0^{d}$ \\
\hline $1(10-11)$ & 2 & Budding of pole cells; blastoderm nuclei reach surface & $350-700$ & $0-1$ \\
\hline II $(11-12)$ & $2-2.5$ & Multiplication of pole cells and blastoderm nuclei & $700-1400$ & $1-2$ \\
\hline III $(12-13)$ & $2.5-3$ & Further multiplication of blastoderm nuclei & $1400-2800$ & $2 \sim 4$ \\
\hline IV $(13-14 a)$ & $3-3.5$ & Onset of infoldings of oolemm between nuclei & $2800-5500$ & $5-7$ \\
\hline$V(14 b)$ & $3.5-4$ & Blastoderm cells separated and elongated & ca. 5500 cells & $5-7$ \\
\hline
\end{tabular}

${ }^{a}$ Arabic numerals in parentheses refer to the stages established by Zalokar and Erk (1976).

${ }^{b}$ Hours after egg deposition, at $25^{\circ} \mathrm{C}$.

Calculated from the scanning electron micrographs of Turner and Mahowald (1976).

${ }^{d}$ Nuclei shielded by cytoplasm and/or yolk. 
plastic foil (Technomara/Zürich, thickness $15 \mu \mathrm{m})$. By sliding the foil on the micro. scope slide, one egg after the other was oriented with its left-hand side uppermost, so that the left chorion filament was superimposed on the right. Then the preselected irradiation site was exposed to the uv beam. After all eggs under the foil had been irradiated, foil and eggs were floated from the slide into rearing dishes. The ensuing larvae were transferred to food vials soon after hatching.

Ultraviolet beam diameter and dose. In the main experimental series on late cleavage and blastoderm stages, doses of $5 \mathrm{erg}$ (corresponding to exposure times of $5 \mathrm{sec}$, see above) were used with beam diameters of 10 or $20 \mu \mathrm{m}$; higher doses and beam diameters were found to cause a larger variability of results. For the germ band irradiations, beam diameters of 20 or $30 \mu \mathrm{m}$ were used in combination with a dose of 10 erg.

Numbers of nuclei or cells irradiated. The nuclei located in circular fields corresponding to the different uv beam diameters were counted with the microscope of the laser setup at different stages. For stages $0-\mathrm{V}$ they varied from 0 to 7 (Table 1 ); in the germ band the numbers were approximately 20 for the $20-\mu \mathrm{m}$ field and approximately 45 for the $30-\mu \mathrm{m}$ field. We assume that these numbers correspond to the numbers of nuclei or cells exposed to effective doses of radiation since uv intensity decreases steeply at the rim of the beam (see inset in Fig. 2; Zorn, 1978) and uv is absorbed strongly by the superficial cytoplasm (Kalthoff, 1971) so that radiation intensity decreases steeply toward any cells located in the interior. Whether all superficial cells in the irradiated area become disabled is an open question. Thus the numbers of initially disabled cells should fall below or within the range of cell numbers postulated by various authors for individual disc anlagen in the embryo [wing disc, 11-40 cells; leg disc, 7-20 cells; haltere disc, less than 20 cells; for references, see Mad- havan and Schneiderman (1978)].

Areas irradiated. Each egg was irradiated at a single site. The position of this spot was varied on preselected profiles. With the early stages, which lack visible landmarks in the embryo, a series of transverse profiles $23 \mu \mathrm{m}$ apart were established, with profile 11 aligned halfway between the egg poles (see horizontal lines in Fig. 1b). The profiles used for the germ band stage were located in each thoracic segment halfway between the anterior and posterior border. For evaluation of results, each profile was subdivided into a ventrodorsal sequence of $23-\mu \mathrm{m}$ sections as shown in Figs. $1 \mathrm{c}$ and $\mathrm{d}$. Each case was assigned to the section where the center of the uv beam was located. The ventrodorsal sections are identified by their dorsal limiting values (e.g., section 2 extends to the left of mark 2 in Fig. 1c). Note that the scale of sections differs between blastoderm and germ band irradiations (Figs. 1c and d).

Types of adult defects. The unmounted flies were checked for external anomalies visible under the dissection microscope (magnification $40 \times$ ). The anomalies noted were scored with reference to the imaginal disc(s) from which the affected structures develop. The most frequent anomaly (65\%) was the apparent absence (as far as can be discerned with the technique used) of the complete set of externally visible structures deriving from a disc. In most other cases only parts of the structures from a disc were missing. There was no obvious indication of defects being restricted to anterior or posterior compartments. Partial duplications as obtained by microcautery of blastoderm stages (Bownes, 1975) or Xray irradiation of older embryos (Postlethwait and Schneiderman, 1973) were very rare. The anomalies were classified as cuticular or functional, respectively. Functional defects are characterized by abnormal posture or movements of otherwise normal-looking cuticular disc derivatives. Typical examples are a wing sticking out laterally from the resting fly or a leg per- 


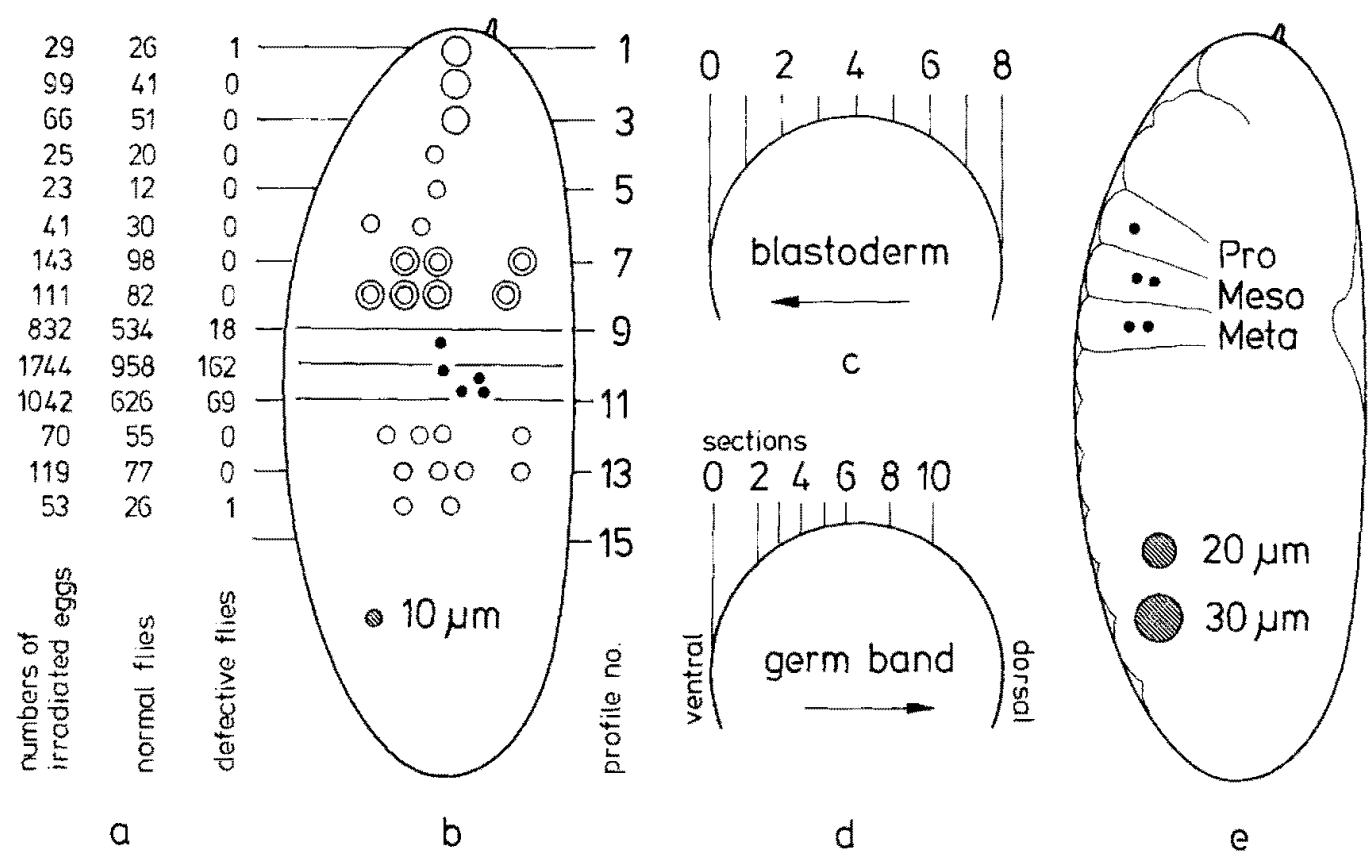

FIG. 1. Classification of results from blastoderm irradiations (a) and reference systems used to localize the laser beam on the egg (b-e). Open circles in (b) indicate the beam locations and beam diameters used on profiles 1-8 and 12-14 of blastoderm stage eggs. On profiles 9-11, which are shown as transverse lines, the beam location was varied to test all sections from 1 to 8 [see (c)]; the beam diameters were 10 or $20 \mu \mathrm{m}$ for these profiles, too. Germ band irradiations (e) were carried out in the thoracic segments (Pro, Meso, Meta) over sections 1-10 (d). Hatched circles represent beam diameters drawn to scale. Black dots in (b) and (e) indicate calculated "target centers" for damage to derivatives of the thoracic discs; for evaluation see Discussion.

manently tucked in under the body. A certain percentage of flies was abnormal in the derivatives of two or three discs. Such "multiple" defects were obtained only from blastoderm irradiations and were scored separately for each disc involved. The external derivatives of the genital disc were never observed to be affected. Anterior to the thorax, the proboscis was the only adult structure occasionally observed to be affected (by irradiation on profiles 8 or 9 ).

Calculation of "target centers" for adult defects. In order to provide a parameter representative of all irradiations causing defects in a particular adult structure, a "target center" for that structure was constructed. The ventrodorsal and, for blastoderm irradiations, also the anteroposterior location of each center were calculated as weighted mean values, thereby compensating for differences in number of eggs irra- diated per individual profiles and sections. The following formula was used:

$$
x=\left(1 / \sum_{i=1}^{n} \alpha_{i}\right) \sum_{i=1}^{n} x_{i} \alpha_{i}
$$

where $x=$ ventrodorsal or anteroposterior location of the center, $n=$ number of ventrodorsal sections or anteroposterior profiles, and $\alpha=$ relative frequency (based on number of irradiated eggs) of adult defects in that particular structure per ventrodorsal section or per profile.

The target centers for the blastoderm stages were calculated exclusively from 10$\mu \mathrm{m}$ irradiations, those for the germ band stage were calculated separately from the 20 - and $30-\mu \mathrm{m}$ irradiations.

Reproducibility of results. Variation between the results from individual eggs was considerable. Part of this variability may be due to technical reasons, e.g., to the fact 
that the blastodermal profiles were separated by constant distances $(23 \mu \mathrm{m})$ irrespective of individual variation in egg length. However, statistical reproducibility appears to be satisfactory since the ventrodorsal locations of the mesothoracic target centers in the germ band were nearly the same when calculated from two entirely independent series (20- and $30-\mu \mathrm{m}$ irradiations).

Controls. A good control for frequency of adult defects arising spontaneously or from technical steps other than exposure to ultraviolet radiation is provided by the nonirradiated (right hand) sides of the irradiated eggs. The overall adult defect frequency on the control side amounted to $0.6-0.7 \%$, with a striking and as yet unexplained preponderance of hind leg defects (Table 2). Only three flies out of some 7000 showed defects on both body sides, and these concerned the forelegs in all cases.

Statistics. Differences in defect yield linked to variation in experimental parameters were tested for significance with the $\chi^{2}$ test at the $P=0.01$ level.
RESULTS

\section{(1) Early Effects of Irradiation}

Immediately after irradiations, whether at blastoderm or germ band, we saw no effect in living or fixed eggs. In eggs irradiated before cellularization the yolk material at the irradiated spot became indented after 30-60 min while the clear periplasm and/or blastoderm increased correspondingly in thickness, but all eggs which eventually yielded viable larvae had regained a normal appearance before or during gastrulation. With irradiations at later stages, we saw no anomalies of early embryogenesis in the living state. In serial sections from some eggs irradiated before blastoderm cellularization (stages I-III) and fixed after cellularization or during gastrulation (1-3 hr after irradiation), the blastodermal layer showed a gap some three to four cells wide. The clear peripheral cytoplasm was thicker in this region than elsewhere, and a zone of structural disturbance extended from there through the yolk system right to the central egg axis (Fig. 2); this zone must reflect some

TABLE 2

Adult Defects Observed on the Control Side (Nonirradiated EgG Side)

\begin{tabular}{|c|c|c|c|c|c|c|c|c|c|}
\hline \multirow[t]{2}{*}{ Stage } & \multirow[t]{2}{*}{$\begin{array}{l}\text { Irradiation } \\
\text { on profiles }\end{array}$} & \multirow[t]{2}{*}{$\begin{array}{l}\text { Eggs irradi } \\
\text { ated }(n)\end{array}$} & \multicolumn{2}{|c|}{$\begin{array}{l}\text { Defective flies } \\
(\%)\end{array}$} & \multicolumn{5}{|c|}{ Defect location } \\
\hline & & & $A^{b}$ & $\mathbf{B}^{c}$ & $\underset{I}{\mathrm{Leg}}$ & $\underset{(n)}{\text { Leg }}$ & $\begin{array}{l}\text { Leg } \\
\text { III } \\
(n)\end{array}$ & $\underset{(n)}{\text { Wing }}$ & $\begin{array}{c}\text { Abdo- } \\
\text { men } \\
(n)\end{array}$ \\
\hline \multirow[t]{4}{*}{ Blastoderm } & $1-8$ & 500 & 0.6 & 0.9 & 0 & 0 & 2 & 0 & 1 \\
\hline & $9-11$ & 5051 & 0.5 & 1 & 2 & 1 & 14 & $8^{d}$ & 2 \\
\hline & $12-14$ & 242 & 0.8 & 1.3 & 0 & 0 & 2 & 0 & 0 \\
\hline & $1-14$ & 5793 & 0.6 & 1 & 2 & 1 & 18 & $8^{d}$ & 3 \\
\hline \multirow[t]{4}{*}{ Germ band } & $\mathrm{I}^{e}$ & 651 & 0.6 & 0.8 & 1 & 0 & 2 & 1 & 0 \\
\hline & II & 720 & 0.5 & 0.6 & 1 & 2 & 0 & 1 & 0 \\
\hline & III & 220 & 1.4 & 1.7 & 1 & 0 & 2 & 0 & 0 \\
\hline & I-III & 1591 & 0.7 & 0.9 & 3 & 2 & 4 & 2 & 0 \\
\hline
\end{tabular}

${ }^{a}$ Blastoderm data pooled from various doses and beam diameters.

' Percentage based on number of irradiated eggs.

"Percentage based on adults obtained.

${ }^{d}$ Of these 3 were functional defects.

'I, II, III = pro-, meso-, metathorax. 


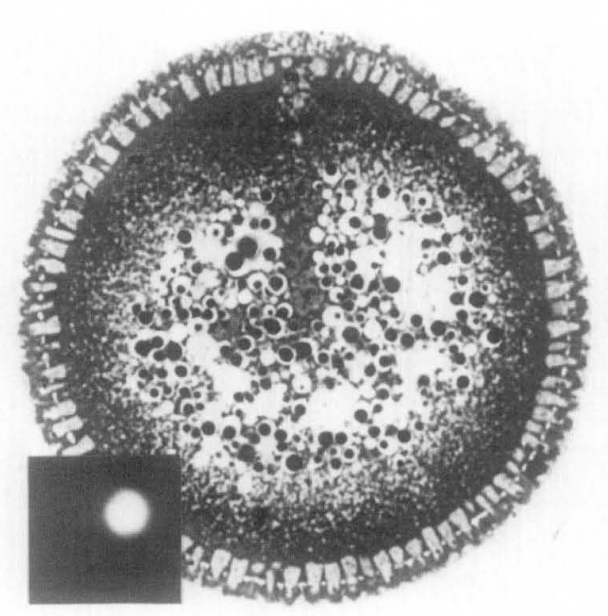

Fig. 2. Transverse 1- $\mu \mathrm{m}$ section from an egg irradiated during stage I, fixed $2 \mathrm{hr}$ later, stained with Toluidine blue; site of irradiation is on top of figure. $270 \times$. Inset: fluorescent spot caused by the uv beam, diameter $=20 \mu \mathrm{m}$ (photomicrograph).

reaction of the system to damage at its surface rather than the course of the uv beam since the latter diverges beyond the focal plane. Somewhat inside the blastoderm layer of the disturbed region we found a group of nuclei which originally may have populated the damaged region (compare Jung, 1971). With irradiation shortly before cellularization, the early effects were even less prominent, but again some nuclei were found just inside the blastoderm in a restricted region probably corresponding to the irradiated spot. After irradiations at the germ band stage, no specific anomalies were noted for several hours. It thus appears that the primary effects of irradiation are fairly slight and localized.

\section{(2) Preadult Mortality}

The percentages of preadult mortality observed after irradiations in different egg regions are listed in Table 3 and Figs. 4 and 5. Preadult mortality from blastoderm irradiations is highest in those regions which yielded the highest percentages of defective flies (profiles 9-11, see below). It is therefore not possible to explain a low yield of
TABLE 3

Preadult Mortality after Irradiation of Different Egg Regions in Blastoderm Stages $\mathrm{I}-\mathrm{V}^{a}$

\begin{tabular}{cccc}
\hline Profiles & $\begin{array}{c}\text { Beam di- } \\
\text { ameter } \\
(\mu \mathrm{m})\end{array}$ & $\begin{array}{c}\text { Eggs irradi- } \\
\text { ated }(n)\end{array}$ & $\begin{array}{c}\text { Mortality } \\
(\%)\end{array}$ \\
\hline \multirow{2}{*}{$1-8$} & 10 & 270 & 23.4 \\
& 20 & 230 & 39.9 \\
$9-11$ & 10 & 3618 & 34.2 \\
& 20 & 1255 & 56.9 \\
$12-14$ & 10 & 242 & 31.4 \\
\hline
\end{tabular}

${ }^{a}$ Dose of uv: 5 erg.

defective adults with an increase in premature death of eggs or larvae destined to produce defective adults. The same is true for the low defect yield from irradiations in the prothorax of the germ band.

Flies unable to hatch were dissected from the puparium and scored with the viable adults.

\section{(3) Adult Defects from Irradiation of Pre. blastoderm and Blastoderm Stages}

A middle region of the egg comprising the profiles 9-11 yielded many more adult defects than the anterior region (profiles 1-8) and the more posterior region comprising profiles 12-14 (Fig. 1a). The few adult defects obtained after irradiations in the latter regions do not exceed significantly the overall defect frequency on the control side (Table 2); they affected the proboscis (profile 8), the hind leg (profiles 13 and 14), and the abdomen (profiles 13 and 14).

Longitudinal spot location and defects in different discs. The frequencies of adult defects in the derivatives of different imaginal discs are statistically linked to the longitudinal location of the uv spot on the blastoderm (Fig. 3). The irradiations on profile 9 yielded defects in pro- and mesothorax (and four proboscis defects not shown in Fig. 3), those on profile 10 defects in all thoracic discs, and those on profile 11 meso- and metathoracic defects. The foreleg was affected with rather equal overall frequencies on profiles 9 and 10 , while mid- 
Prothorax
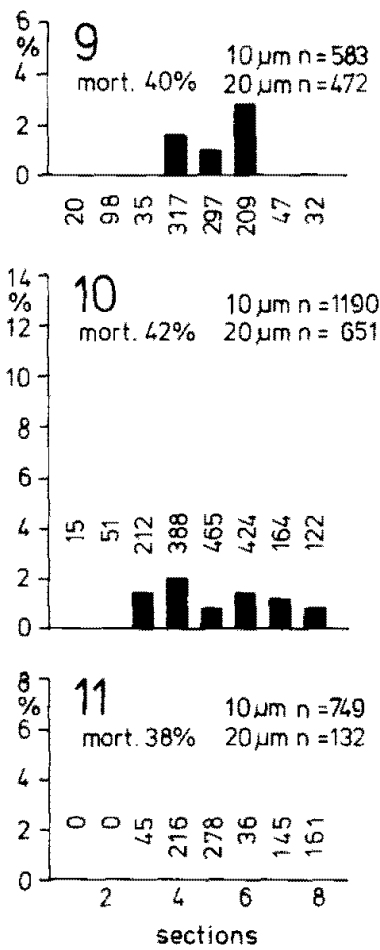

Mesothorax
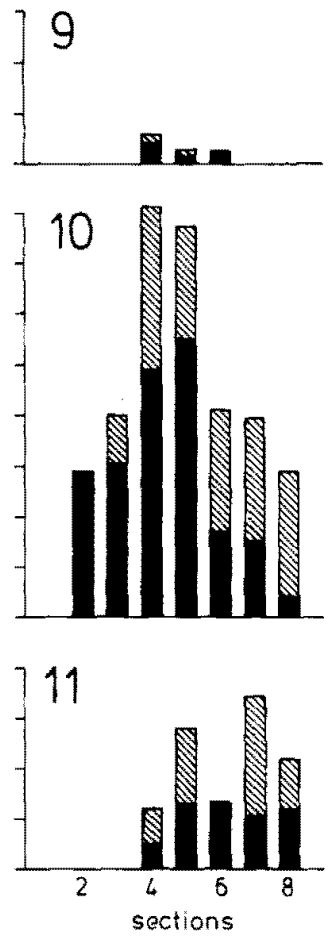

Metathorax
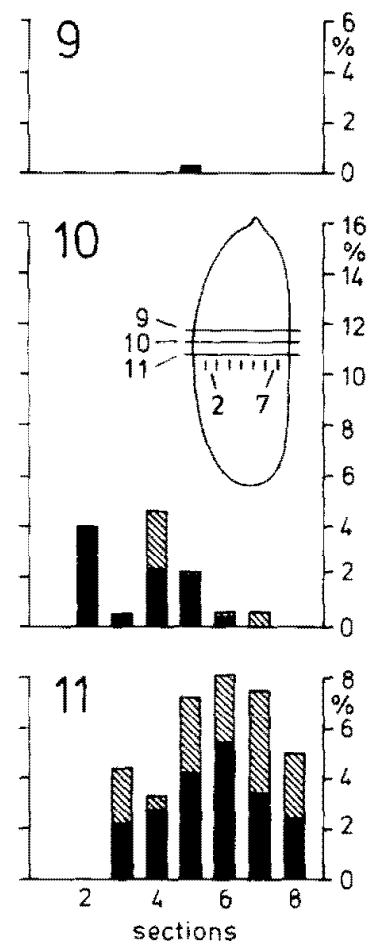

Fig. 3. Adult defect frequencies in the three thoracic segments (Pro-, Meso-, and Metathorax) after irradiations on blastoderm profiles 9 (top), 10 (middle), and 11 (bottom), scored per ventrodorsal section (abscissa, see inset). Black parts of columns indicate leg defects, hatched parts indicate wing/notum or haltere defects (meso- and metathorax, respectively); the proboscis defects obtained (four cases on profile 9) are not shown. Frequencies based on numbers of irradiated eggs per section (see left column). $n=$ Number of eggs irradiated with beam diameters of 10 or $20 \mu \mathrm{m}$ on the respective profiles; mort = preadult mortality. The numbers of irradiated eggs are higher than in Fig. Ia due to some subsequent series not incorporated there.

dle leg and wing/mesonotum defects appeared with maximum frequency after irradiations on profile 10 . Hind leg and haltere defects had their respective maxima on profile 11 but mesothoracic disc defects were as frequent as metathoracic defects on this profile. The relative contributions of meso- and metathoracic defects to the total defect yield differ significantly between profiles 10 and 11 .

Ventrodorsal spot location and defects in different discs. The distribution of columns on the abscissae in Fig. 3 shows that few if any adult cuticular defects resulted from irradiations in the most ventral sections 1 and 2. The maximum overall defect yield was obtained between sections 4 and 7 , that is, after irradiations in lateral or dorsal-lateral locations. On profile 11 the maximum overall defect yield came clearly from more dorsal irradiations than on the other profiles. The overlap of damage to ventral (black columns) and dorsal disc derivatives (hatched) was quite considerable, with very few sections yielding exclusively ventral or dorsal disc effects. The relative contributions of ventral and dorsal disc defects to the total defect yield did not differ significantly between adjacent sections, except the most ventral and dorsal sections affecting the mesothorax.

A map of blastodermal target centers for adult defects in different imaginal discs. A blastodermal "target center" was calculated for each thoracic disc. The positions of these centers are indicated in Fig. $1 \mathrm{~b}$ as 
black discs. The longitudinal positions of the target centers expressed as percentage of egg length $(\% \mathrm{EL}$, with $0 \% \mathrm{EL}$ at the posterior egg pole) are as follows: foreleg disc $57.2 \%$, middle leg disc $53.8 \%$, hind leg disc $51 \%$, wing disc $52.8 \%$, and haltere disc $51 \% \mathrm{EL}$. The absolute distances between adjacent centers range from approximately $16 \mu \mathrm{m}$ (first/second leg) to $9 \mu \mathrm{m}$ (wing/ haltere). Thus, the calculated target centers are very few cell diameters apart. Whether these centers are representative for the average locations of the respective disc progenitor cells will be discussed below. But it should be pointed out already here that the dorsoventral distances shown on the map are probably smaller than the average distances between the respective progenitor cells.

\section{(4) Adult Defects from Irradiation at the Germ Band Stage}

The germ band irradiations were aimed exclusively at the thoracic segments which are visibly delineated by furrows thought to mark the segment borders. The observed adult defects were restricted to the irradiated segment.

Ventrodorsal spot location and defect frequency. Irradiations over the full range of sections 1-10 (Fig. 1d) were carried out only in the mesothorax and with the $30-\mu \mathrm{m}$ spot. The bulk of adult defects resulted from irradiations in sections 3,4 , and 5 (Fig. 4). The distribution of spots causing leg defects was more ventral than the distribution for wing disc defects. With $20 \mu \mu \mathrm{m}$ irradiations in sections $1-5$, comparable distributions were obtained for meso- and metathorax while for the prothorax the defect yield was much lower and the maximum defect frequency resulted from irradiations in sections $1+2$ (Fig. 5). To check whether these deviations were due to strongly ventral positions of the foreleg precursor cells, we irradiated ventral and ventrolateral locations from the ventral egg side. Sixty eggs irradiated in the prothorax yielded 54 flies, all without apparent defects. From 20 eggs irradiated likewise in the mesothorax, we obtained 13 flies; these all had normal legs but three displayed functional defects affecting the wing. Thus the low defect yield from lateral irradiations in the prothorax must be due to some cause other than the rather ventral position of the foreleg anlage.

Longitudinal spot location and defect frequency. In the germ band irradiations described so far, the beam center was aligned halfway between the visible anterior and posterior borders of the respective segment. In order to check for consequences of irradiations in more anterior or more posterior regions of the segment, we

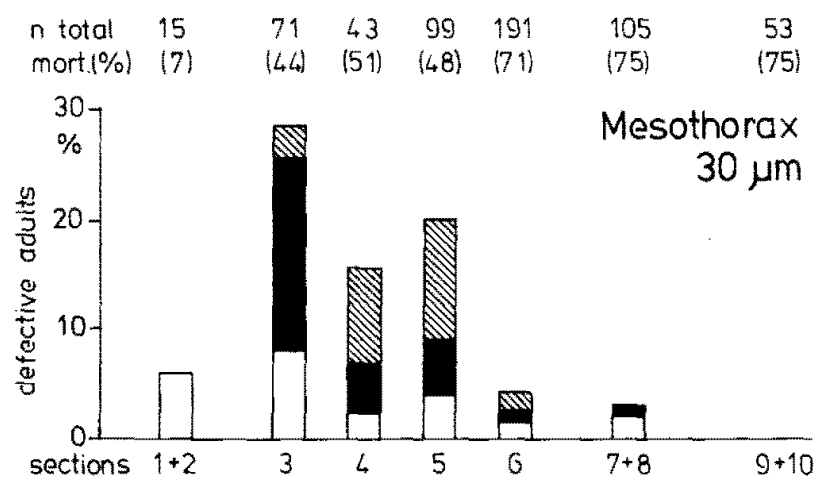

Fra. 4. Adult defects from $30-\mu \mathrm{m}$ irradiations in the mesothorax of the germ band stage, scored per ventrodorsal section (see Fig. 1d). Percentages based on numbers of irradiated eggs (top). White parts of columns indicate functional defects; black parts, leg defects; hatched parts, dorsal disc defects. Preadult mortality shown below egg number. 

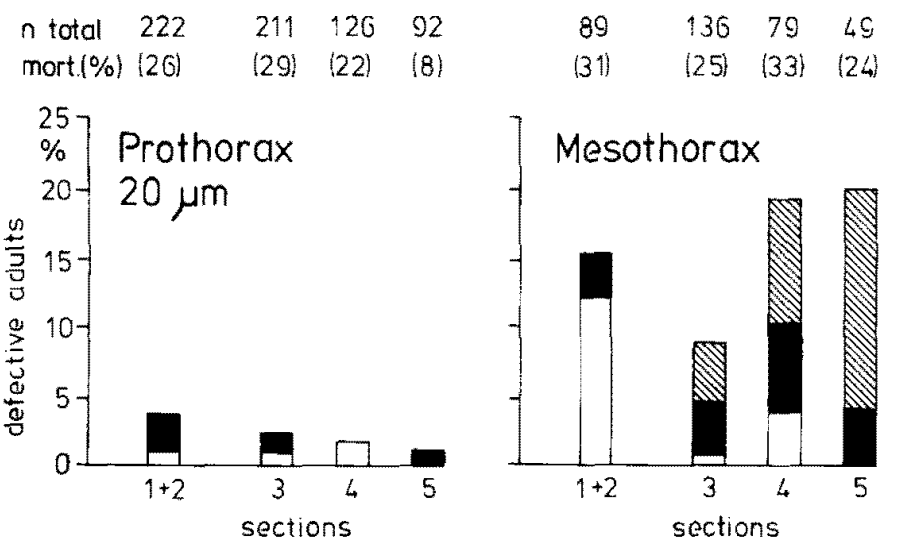

$\begin{array}{cccc}15 & 78 & 96 & 66 \\ 10) & (23) & (21) & (10)\end{array}$

Fig. 5. Adult defects from $20-\mu \mathrm{m}$ irradiations in pro-, meso-, and metathorax of the germ band stage, scored per ventrodorsal section. Same symbols as in Fig. 4.

irradiated 69 eggs with the beam centered on the anterior or on the posterior border of the mesothoracic segment in sections 3 or 4 . All 57 hatched flies were free of apparent defects whereas irradiation of 215 embryos in the same sections but halfway between segment borders yielded 27 defective flies (Fig. 5) - a highly significant difference.

A map of target centers for imaginal discs in the germ band. The result just described indicates that in the germ band the target centers for damage to imaginal discs are located centrally in the segments rather than close to the segment borders. The precise anteroposterior locations were not established; in the map (Fig. 1e) we therefore place the centers halfway between segment borders.

The ventrodorsal location of each target center in the map (Fig. 1e) was calculated from the $20-\mu \mathrm{m}$ irradiations (Fig. 5). The foreleg center mapped at $25 \mu \mathrm{m}$ from the ventral egg contour. In the meso- and metathorax, the target centers for leg defects mapped $39 \mu \mathrm{m}$ from the ventral egg contour, and the centers for dorsal defects mapped at $50 \mu \mathrm{m}$. The corresponding values calculated from the $30-\mu \mathrm{m}$ irradiations in the mesothorax (Fig, 4) were $37 \mu \mathrm{m}$ for leg defects and $52 \mu \mathrm{m}$ for wing disc defects. It should be noted that the values for mesoand metathorax and particularly those for the dorsal discs could be biased toward the ventral (see Discussion).

\section{DISCUSSION}

The correlations observed between site of irradiation and location of adult defects have been used to construct "defect maps" for the irradiated stages (Figs. $1 \mathrm{~b}$ and e). The "target centers" constituting these maps have a statistical basis and thus may be subject to errors caused by the technical procedure or by inherent properties of the developing system. Therefore they need to be interpreted with caution, particularly since we were unable to directly observe (or otherwise establish) the chain of events linking embryonic radiation damage and adult defect. Yet we shall first take the bona fide view that the defect maps reflect without bias the location of the respective disc progenitor cells at the time of irradiation. Thereafter, some possible complications of interpretation will be discussed.

In our defect maps for the blastoderm stage, the array of target centers (black dots in Fig. 1b) is tolerably compatible with the distribution of the respective anlagen in fate maps obtained with the mosaic technique (see review of Hall et $\mathrm{al}$, 1976). However, the distances between the centers are considerably smaller than in early mosaic fate maps which, besides locating the adult anlagen relative to each other, also showed 
egg contours (e.g., Hotta and Benzer, 1972; Ripoll, 1972). But more recent data from mosaic flies agree with the comparably small distances in our map; the thoracic disc anlagen are now thought to be contiguous, with few if any prospective larval cells in between (Wieschaus and Gehring, $1976 \mathrm{~b})$. Since the estimates of cell numbers per blastodermal leg disc anlage vary from 6 (Wieschaus and Gehring, 1976a) to 20 (Garcia-Bellido and Merriam, 1969), the centers of adjacent leg anlagen should be three to six cell diameters apart if each anlage is hexagonal in shape. This estimate agrees tolerably with our defect map where the distances between the leg centers equal approximately three cell diameters. The distances between ventral and dorsal target centers are also fairly compatible with the reported numbers of progenitor cells. The distance between the centers for wing disc and haltere disc, on the other hand, is too small even for a very low number of haltere progenitor cells. This is possibly due to the fact that we were unable to induce any adult defects posterior to profile 11 (see below).

Our defect map for the germ band stage (Fig. 1e) shows the target centers in more ventral positions than on the blastoderm. This difference is easily explained by the fact that gastrulation occurs in between these stages and removes the more ventral regions of the blastoderm from the surface. The foreleg center occupies a more ventral position than the other leg centers. To judge from the distribution of foreleg defects over the individual sections (Fig. 5), this difference is not due to a sampling error of the kind suspected for the other segments (see below). We therefore assume that both the low defect yield and the ventral location of the target center in the prothorax are linked to the temporary fusion of both foreleg anlagen across the ventral midline (Steiner, 1976); in this process, the progenitor cells might move toward the ventral midline and sink below the surface where they would be shielded from the uv radiation. The distances between ventral and dorsal discs are smaller in the germ band than in the blastoderm map, possibly because the disc anlagen have started to change shape. Alternatively, a sampling error might have pushed the values for the dorsal centers toward the ventral, since dorsal to section 5 there were no irradiations (Fig. 5), or mortality was so high (Fig. 4) that it could have masked many adult defects simultaneously induced. The rather lateral positions of the meso- and metathoracic target centers challenge the conclusion of Geigy (1932) that the thoracic disc anlagen are located ventrally in the germ band, as does our failure to induce adult defects (other than functional) by irradiations from the ventral egg side. Geigy's conclusion was based on unilateral irradiation of the entire egg and this may account for the differences in interpretation.

As pointed out above, the relations between local uv damage and adult defect may be less straightforward than implied so far. This is indicated by several observations; for example, the irradiated cells are not destroyed at once, the defect yield varies in a continuous fashion over the different blastoderm stages (Lohs-Schardin, $1977)$, and $10-\mu \mathrm{m}$ irradiations on the blastoderm frequently lead to multiple adult defects while the irradiation of much larger areas (diameter, 20 or $30 \mu \mathrm{m}$ ) on the germ band never affected the cuticular derivatives of more than a single disc. The bearing, if any, of these observations on mapping remains obscure at present, but there are other reactions of the developing system which conceivably might bias the mapping procedure. We will discuss two of these, namely, interaction or cooperation between different progenitor cells and regional differences in uv susceptibility.

Cooperation between distant cell groups of differing prospective fates is indicated by the tendency of "functional" adult defects to map more ventrally than the cuticular anomalies affecting the same discs. Functional defects might thus originate from 
damage to progenitor cells of muscles or nerves serving the respective cuticular structures. For the mapping procedure, this difference does not matter since these defects were rather infrequent. Matters may be different when cooperation between spatially contiguous cell populations of different prospective fates, such as progenitors for leg and wing disc, respectively, is considered. Defects in the adult derivatives of ventral and dorsal discs can be induced side by side over a wide range of blastodermal sections (see black and hatched columns in Fig. 3). This zone of overlap is much larger than that for defects in different segments. For instance, middle leg and wing disc defects were induced over some $130 \mu \mathrm{m}$ (sections 3-8) while the region yielding both foreleg defects and middle leg defects was restricted to profiles 9 and 10 , that is, was barely $50 \mu \mathrm{m}$ wide (allowing for half the unit distance of $23 \mu \mathrm{m}$ on either side of these profiles); and the defect spectra from adjacent profiles differ significantly while those from adjacent sections as a rule do not. These differences may indicate that at blastoderm the ventral and dorsal anlagen of the same segment are functionally less strongly separated than the adult anlagen of adjacent segments. More specifically, the crippling of a cell whose progeny in the unirradiated egg would have contributed to the leg disc might cause the progeny of an adjacent cell to contribute to leg rather than wing disc-with the consequence that a wing disc defect would result (and vice versa). With this kind of interaction within the same segment, the target centers calculated for ventral and dorsal disc defects would be strongly biased toward a common center representative for the entire population of adult progenitors in the segment; that is, the distances between ventral and dorsal centers would be underestimated in our map. To some degree this must necessarily follow from the multiple defects affecting ventral and dorsal discs after irradiation of a single site.

These notions are compatible with the finding that at blastoderm the ventral and dorsal adult progenitor cells within a segment are not yet separated by compartmental restrictions (Wieschaus and Gehring, 1976a). They also bear out the warning of Lawrence and Morata (1977) that separate structures derived from a single polyclone must not be used to calculate separate anlage positions. Accordingly, if it were not for comparison with earlier fate maps, our map for the blastoderm stage should show only a single target center for each thoracic segment located halfway between the respective ventral and dorsal centers shown in Fig. 1b. The adult anlage represented by this center could then be considered functionally uniform, except perhaps near its ventral and dorsal margins where chances are small that in case of the interaction outlined above a disabled prospective leg disc is replaced by a prospective wing disc cell, or vice versa.

The assumption of a single adult anlage per segment could solve a riddle posed by our data, namely, the differences in defect frequency observed between different thoracic discs after blastoderm irradiations. The middle leg was affected at least twice as frequently as the other legs (Fig. 3). With the traditional explanation, which links the probability of a hit to the size of the target (Becker, 1957), this finding would indicate strong differences in size of the blastodermal anlagen for different legs-a rather unlikely assumption. However, the explanation can be retained if one defines the target as the sum of prospective adult cells per body segment. In this case the data make more sense. The mesothorax, which yields the highest percentage of adult defects (Fig. 3 ), is generally assumed to derive from the largest number of adult progenitor cells in the blastoderm (see Madhavan and Schneiderman, 1978), while the prothorax combines the lowest defect yield with the smallest number of blastodermal adult progenitor cells. Quantitatively, the defect frequencies do not exactly parallel the assumed progenitor cell numbers, but this may be 
due to interaction with adjacent larval cells.

However, further considerations are required because of our failure to induce adult defects by irradiations anterior and posterior to profiles $9-11$ on the blastoderm (Figs. la and b). Such differential uv sensitivity, observed also in other insect eggs (Seidel, 1961; Jung, 1971), is noteworthy because it could bias mean values calculated from irradiations spread over regions covering a gradient in uv sensitivity (see Fig. 13 in Sander, 1976); the bias would be toward the region with maximum uv sensitivity, represented in our data by profile 10 (highest preadult mortality and highest adult defect frequency). Yet, the calculated centers should remain within the limits of the respective segment anlagen, and therefore the resulting error cannot be very large. This is also indicated by a recent map based on larval defects (Lohs-Schardin and Nüsslein-Volhard, unpublished) which agrees well with our map although larval defect frequency varied much less from region to region than adult defect frequency in our data.

To summarize, we feel that the longitudinal value for the mesothoracic target centers (approximately 53-54\% EL) is representative for the longitudinal position of the mesothoracic adult progenitor cells in the blastoderm and that the corresponding values for pro- and metathorax (approximately 57 and $51 \%$ EL) are not strongly biased. The same should hold true for the longitudinal positions of the target centers obtained from germ band irradiations. The distance between ventral and dorsal target centers in a segment, on the other hand, may be smaller than the average distances between the cells from which the respective discs derive: on the blastoderm map because the segment anlage at that stage might not yet contain two functionally differing populations of adult progenitor cells, and on the germ band map because of limited sampling in more dorsal regions.

Whatever their shortcomings, the defect maps for adult anlagen obtained with the microbeam laser provide far more detailed and accurate information than earlier attempts at fate mapping with the aid of local lesions (Hathaway and Selman, 1961; Nöthiger and Strub, 1972; Bownes and Sang, 1974a,b; Mertens, 1977). Compared with the elegant mosaic mapping technique, our method so far provides less information concerning different regions within a disc. But mosaic frequencies determined for different structures deriving from the same disc or compartment may have little topo. graphical meaning when projected on the blastoderm (Wieschaus and Gehring, 1976a; Lawrence and Morata, 1977).

As the main advantage of our mapping method we count the possibility to obtain, with judicious interpretation, the real rather than relative locations of adult progenitor cells in blastoderm and germ band. We therefore believe that defect mapping with the uv laser microbeam will usefully complement the results obtained with the established mosaic mapping techniques.

The authors warmly thank Mrs. M. Scherer for her invaluable help in typing and preparing the diagrams. Very helpful comments on earlier versions of the manuscript were contributed by C. M. Bate, P. A. Lawrence, and Ch. Nüsslein-Volhard whom we wish to thank here.

\section{REFERENCES}

Becker, H. J. (1957). Über Röntgenmosaikflecken und Defektmutationen am Auge von Drosophila und die Entwicklungsphysiologie des Auges. Z. Indukt. Abstamm. Vererbungsl. 88, 333-373.

Bownes, M. (1975). Adult deficiencies and duplications of head and thoracic structures resulting from microcautery of blastoderm stage Drosophila embryos. J. Embryol. Exp. Morphol. 34, 33-54.

Bownes, M., and Kalthoff, K. (1974). Embryonic defects in Drosophila eggs after partial UV irradia. tion at different wavelengths. $J$. Embryol. Exp. Morphol. 31, 329-345.

Bownes, M., and SANG, J. H. (1974a). Experimental manipulation of early Drosophila embryos. I. Adult and embryonic defects resulting from microcautery at nuclear multiplication and blastoderm stages. $J$. Embryol. Exp. Morphol. 32, 253-272.

Bownes, M., and SANG, J. H. (1974b). Experimental manipulation of early Drosophila embryos. II. Adult and embryonic defects resulting from the removal of blastoderm cells by pricking. J. Embryol. Exp. 
Morphol. 32, 273-285.

Cremer, Ch., Zorn, Ch., and Cremer, Th. (1974). An ultraviolet laser microbeam for $257 \mathrm{~nm}$. Microsc. Acta 75, 331-337.

Garcia-Bellido, A., and Merriam, J. R. (1969). Cell lineage of the imaginal discs in Drosophila gynandromorphs. $J$. Exp. Zool. 170, 61-76.

Gergx, R. (1931). Action de l'ultra-violet sur le pôle germinal dans l'ouf de Drosophila melanogaster. Rev. Suisse Zool. 38, 189-288.

GeIGy, R. (1932). Erzeugung rein imaginaler Defekte am Ei durch UV-Bestrahlung bei Drosophila melanogaster. Wilhelm Roux Arch. 125, 406-447.

Hall, C. J., Gelbart, W. M., and Kankel, D. R. (1976). Mosaic systems. In "The Genetics and Biology of Drosophila" (M. Ashburner and E. Novitski, eds.), Vol. 1A, pp. 265-308. Academic Press, New York.

Hathaway, D. S., and SelmaN, G. G. (1961). Certain aspects of cell lineage and morphogenesis studied in embryos of Drosophila melanogaster with an ultraviolet microbeam. J. Embryol. Exp. Morphol. 9, 310-325.

HEGNER, R. W. (1910). Experiments with chrysomelid beetles. Biol. Bull. 19, 18-30.

HotTA, Y., and BENZER, S. (1972). Mapping of behaviour in Drosophila mosaics, Nature (London) 240, $527-535$.

Howland, R. B., and CHILD, G. P. (1935). Experimental studies on development in Drosophila melano. gaster. II. Regulation in the early egg. J. Exp. Zool. $73,109-125$.

JUNG, E, (1971). Die Entwicklungsfahigkeit des Eies von Bruchidius obtectus SAY nach partieller UV. Licht-Bestrahlung (Coleoptera), Wilhelm Roux Arch. 167, 299-324.

Kalthoff, K. (1971). Position of targets and period of competence for UV-induction of the malformation "double abdomen" in the egg of Smittia spec. (Diptera, Chironomidae). Wilhelm Roux Arch. 168, 63-84.

LAWRENCE, P., and Morata, G. (1977). The early development of mesothoracic compartments in Dro. sophila. An analysis of cell lineage, fate mapping, and an assessment of methods. Develop. Biol. 56, $40-51$.

LOHS-SCHARDIN, M. (1977). "Kartierung imaginaler Anlagen in Drosophila-Embryonen durch UV. Mikro-Bestrahlung." Thesis, Universität Freiburg.

Madhavan, M. R., and Schneiderman, H. A. (1978). Histological analysis of the dynamics of growth of imaginal discs and histoblast nests during the larval development of Drosophila melanogaster. Wilhelm Roux Arch. 183, 269-306.

Mertens, M. (1977). Larval and imaginal defects after pricking of blastoderm stages: experiments complementary to morphogenetic fate maps of Drosophila. Drosophila Inform. Serv, 52, 134.

Nóthiger, R., and Strus, S. (1972). Imaginal defects after UV-microbeam irradiation of early cleavage stages of Drosophila melanogaster. Rev. Suisse Zool. 79, 267-279.

Postlethwait, J. $\mathrm{H}$, and Schneiderman, $H$. A. (1973). Pattern formation in imaginal discs of Drosophila melanogaster after irradiation of embryos and young larvae. Develop. Biol. 32, 345-360.

Rupoli, P. (1972). The embryonic organization of the imaginal wing dise of Drosophila melanogaster. Wilhelm Roux Arch. 169, 200-215.

SANDER, K. (1976). Specification of the basic body pattern in insect embryogenesis. Advan. Insect Physiol. 12, 125-238.

SEIDEL, F. (1935). Der Anlagenplan im Libellenei, zugleich eine Untersuchung über die allgemeinen Bedingungen für defekte Entwicklung und Regulation bei dotterreichen Eiern. Wilhelm Roux Arch. 132, 671-751.

SEIDEL, F. (1961). Entwicklungsphysiologische zentren im eisystem der Insekten. Zool. Anz. Suppl. 24, 121-142.

STEINER, E. (1976). Establishment of compartments in the developing leg imaginal discs of Drosophila melanogaster. Wilhelm Roux Arch. 180, 9-30.

Turner, T. R., and Mahowald, A. P. (1976). Scanning electron microscopy of Drosophila embryogenesis. 1. The structure of the egg envelopes and the formation of the cellular blastoderm. Develop. Biol. $50,95-108$.

Wieschaus, E., and Gehring, W. (1976a). Clonal analysis of primordial disc cells in the early embryo of Drosophila melanogaster. Develop. Biol. 50, 249-263.

Wieschaus, E., and Gehring, W. (1976b). Gynandromorph analysis of the thoracic dise primordia in Drosophila melanogaster. Wilhelm Roux Arch. 180, $31-46$.

ZALOKAR, M., and ERK, I. (1976). Division and migration of nuclei during early embryogenesis of Drosophila melanogaster. J. Microscopie Biol. Cell. 25, $97-106$.

ZORN, Cr. (1978). "UV Mikrobestrahlungsexperimente zur synergistischen Chromosomenschädigung durch ultraviolettes Licht und Coffein." Thesis, Universität Freiburg. 